MARCIA MARIE MARU

\title{
ESTUDO DO DESGASTE E ATRITO DE UM PAR \\ METÁLICO SOB DESLIZAMENTO LUBRIFICADO
}

Tese apresentada à Escola Politécnica da Universidade de São Paulo para a obtenção do Título de Doutor em Engenharia

São Paulo

2003 


\section{MARCIA MARIE MARU}

\section{ESTUDO DO DESGASTE E ATRITO DE UM PAR METÁLICO SOB DESLIZAMENTO LUBRIFICADO}

Tese apresentada à Escola Politécnice da Universidade de São Paulo para a obtenção do título de Doutor em Engenharia

Área de concentração:

Engenharia Mecânica

Orientador:

Prof. Titular

Dr. Deniol Katsuki Tanaka

São Paulo

2003 
FICHA CATALOGRÁFICA

Maru, Marcia Marie

Estudo do desgaste e atrito de um par metálico sob

deslizamento lubrificado / Marcia Marie Maru. -- São Paulo, 2003. $254 \mathrm{p}$.

Tese (Doutorado) - Escola Politécnica da Universidade de São Paulo. Departamento de Engenharia Mecânica.

1.Desgaste 2.Atrito 3.Lubrificante parafínico 4.Contaminante abrasivo 5.Lubrificação mista 6.Movimento rotativo 7.Movimento oscilatório 8.Carregamento mecânico l.Universidade de São Paulo. Escola Politécnica. Departamento de Engenharia Mecânica II.t. 


\section{AGRADECIMENTOS}

À Fapesp, pelo financiamento deste trabalho através do projeto 97/12753-9 (bolsa de doutorado).

Ao Prof. Dr. Deniol Katsuki Tanaka, por sua orientação, confiando-me a realização deste trabalho com liberdade e autonomia.

Ao Prof. Dr. Roberto Martins de Souza, pelas proveitosas sugestões nas várias etapas de realização deste trabalho.

Ao Prof. Dr. Amilton Sinatora, Prof. Dr. Linilson R. Padovese e Prof. Dr. João Telésforo N. de Medeiros, pelas sugestões, incentivo, preocupação e apoio durante este período.

Ao Dr. Eduardo Tomanik, da empresa Mahle, pela participação nas discussões deste trabalho, e ao pessoal do Laboratório de Metrologia da Mahle, pela realização das medições de perfil das amostras metálicas.

À Dra. M ${ }^{\mathrm{a} .}$ Adelina Araújo, da empresa Petrobrás, pela atenção e apoio durante a estadia no Centro de Pesquisas - Cenpes, pelo fornecimento do óleo neutro para as amostras de ensaio e pelas discussões sobre lubrificantes, e ao pessoal técnico do Cenpes, pelo apoio nas caracterizações de óleo.

Ao Eng. Tarcísio Baroni, da empresa Tribolab, pelas análises de óleo e pelas discussões realizadas.

Ao Prof. Dr. André P. Tschiptschin e à Enga. MSc. Clarice Kunioshi, do Depto. de Eng. Metalúrgica e de Materiais, pela permissão e realização da microscopia eletrônica de varredura.

À Silene e ao Sidney M. Carneiro da Silva, pela paciência, apoio e compreensão.

Aos colegas técnicos, engenheiros, mestrandos e doutorandos do Laboratório de Fenômenos de Superfície (LFS) e do Laboratório de Dinâmica (LADIN) do Depto. de Eng. Mecânica, e do Laboratório de Metalografia do Depto. de Eng. Metalúrgica e de Materiais, pelas experiências compartilhadas e pelo companheirismo, solidariedade e paciência que me foram destinados durante momentos importantes e pelas discussões, tanto acerca do tema deste trabalho, como nos trabalhos em conjunto realizados. 
A meus pais

pela compreensão e apoio incondicionais 


\section{SUMÁRIO}

\section{RESUMO}

ABSTRACT

\section{LISTA DE SÍMBOLOS}

\section{LISTA DE FIGURAS}

LISTA DE TABELAS

\section{LISTA DE EQUAÇÕES}

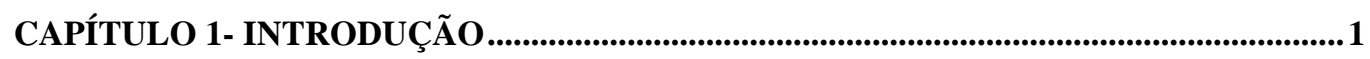

CAPÍTULO 2 - REVISÃo BIBLIOGRÁFICA ..........................................................................

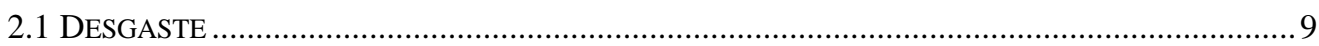

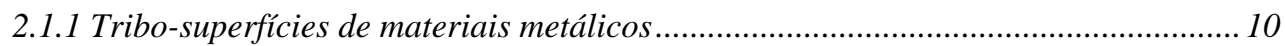

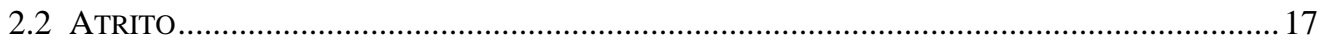

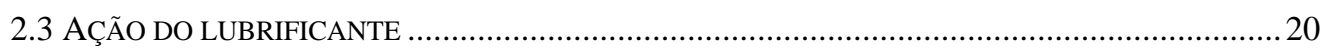

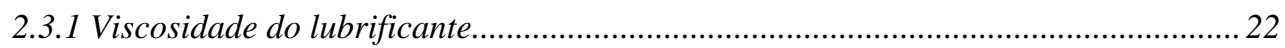

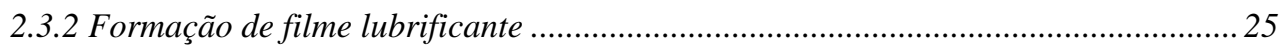

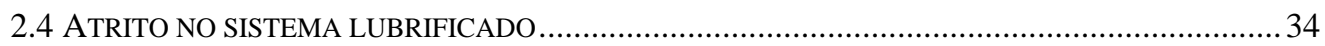

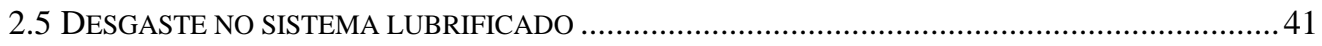

2.6 CONSIDERAÇÕES SOBRE A COMPOSIÇÃO DO ÓLEOS LUBRIFICANTES ....................................4

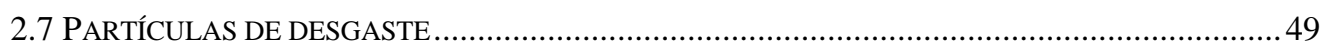

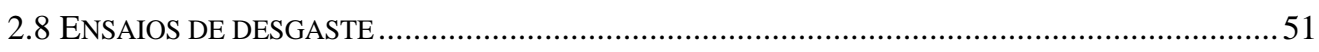

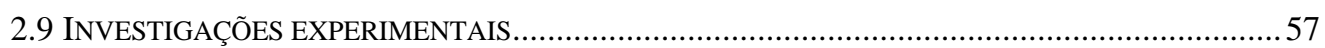

2.9.1 Desempenho triboquímico de filmes lubrificantes .....................................................58

2.9.2 Influência da rugosidade no desgaste lubrificado ..................................................67

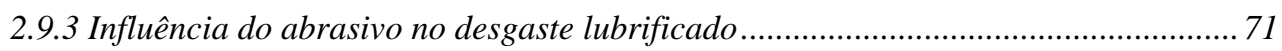

2.9.4 Desgaste e atrito relacionados com regimes de lubrificação ..................................... 78

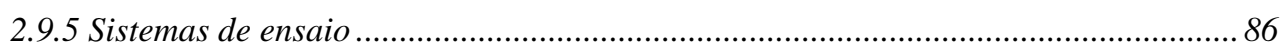

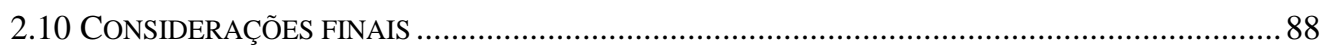

CAPÍTULO 3 - MATERIAIS E MÉTODOS ................................................................................89

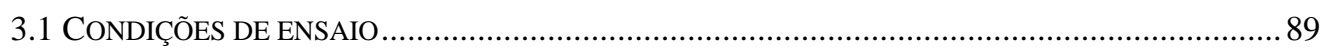

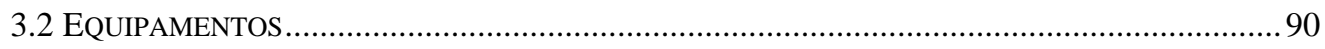

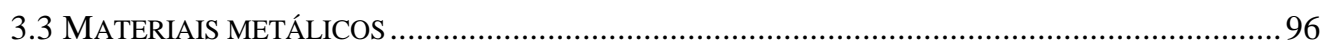

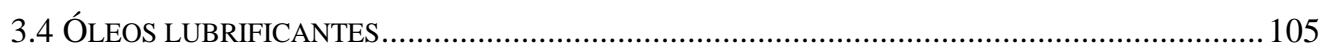

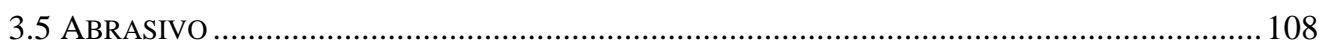

3.6 PROCEDIMENTOS PARA OS ENSAIOS DE DESLIZAMENTO ...................................................110 
CAPÍTULO 4 - RESULTADOS E DISCUSSÃo ..................................................................114

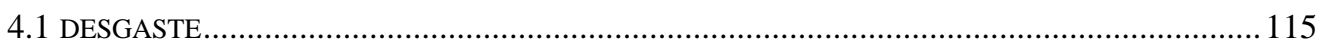

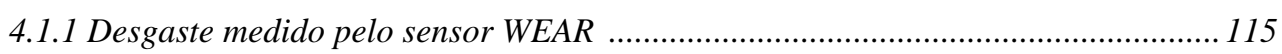

4.1.2 Considerações sobre o cálculo do volume de desgaste do pino ...............................118

4.1.3 Morfologia microscópica das superfície.............................................................. 121

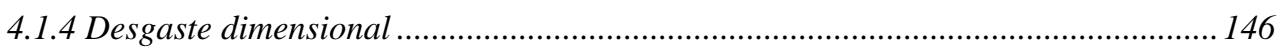

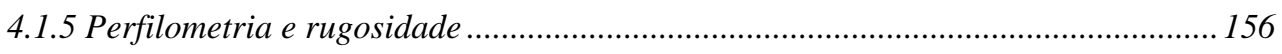

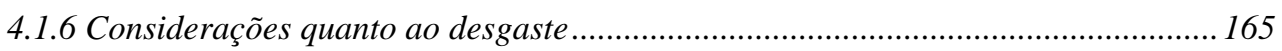

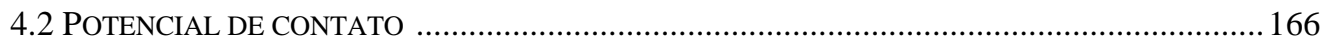

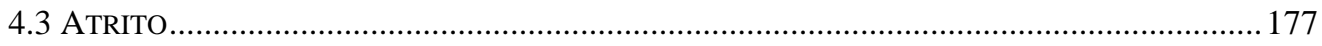

CAPÍTULO 5 - DISCUSSÃO GERAL .................................................................................188

5.1 CARACTERÍSTICAS DE INFLUÊNCIA DOS SISTEMAS DE ENSAIO NO DESEMPENHO

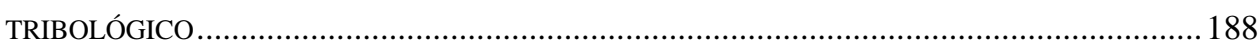

5.2 INFLUÊNCIA DO MOVIMENTO E DO FLUXO DE ÓLEO NA INTERFACE DESLIZANTE................. 191

5.3 DESGASTE EM FUNÇÃO DO CARREGAMENTO MECÂNICO ................................................... 192

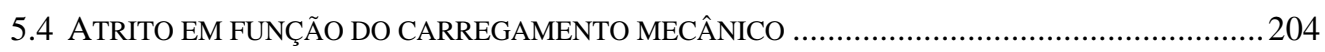

5.5 ESPESSURA DO FILME DE LUBRIFICANTE NA INTERFACE …….........................................2. 205

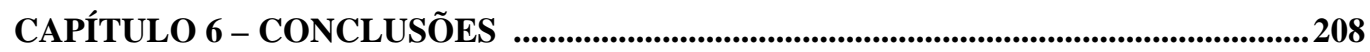

ANEXO A: MORFOLOGIA MICROSCÓPICA DAS AMOSTRAS ENSAIADAS ....................................213

ANEXO B: RESULTADOS DO COEFICIENTE DE ATRITO E DO POTENCIAL DE CONTATO

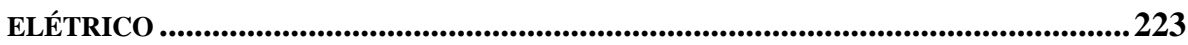

ANEXO C: RESULTADOS DA ANÁlISE DO ÓLEO ...........................................................................233

ANEXO D: CARACTERIZAÇão daS PARTículas de DESGaSTE .................................................239

ANEXO E: INFLUÊNCIA DA RUGOSIDADE INICIAL - DIFERENÇA ENTRE OS LOTES..................245

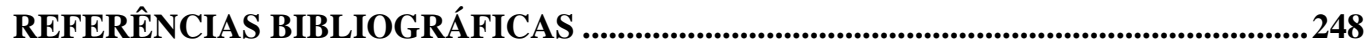




\section{RESUMO}

Este trabalho trata de um estudo experimental das respostas de desgaste e de atrito encontradas em um sistema deslizante lubrificado. Para tanto, foram realizados ensaios de deslizamento em um equipamento para ensaios de desgaste, adotando-se o dispositivo pino-contra-disco, para ensaios com movimento relativo rotativo contínuo entre as amostras, e o dispositivo pino-contra-placa, para ensaios com movimento relativo alternado, ou oscilatório, entre as amostras. Os materiais metálicos ensaiados foram pinos de aço AISI 52100 e contra-corpos de aço AISI 8640. O óleo lubrificante foi o mineral de base parafínico, IV 100. Foram variadas as condições de aditivação e de contaminação do óleo lubrificante e foram utilizados dois níveis de carregamento mecânico, determinada pela relação velocidade/carga. $\mathrm{O}$ desgaste foi estudado por microscopia óptica e eletrônica de varredura, medição da área afetada pelo desgaste, perfilometria das superfícies desgastadas e análise de óleo. O atrito e o potencial de contato foram monitorados ao longo dos ensaios. Os resultados obtidos mostraram que o desgaste dos corpos metálicos foi sensível ao carregamento mecânico, à aditivação e à contaminação do óleo. Diferenças foram notadas nas morfologias superficiais entre os resultados de desgaste dos ensaios rotativos e oscilatórios.

Palavras-chave: desgaste, atrito, lubrificante parafínico, contaminante abrasivo, movimento rotativo, movimento oscilatório, carregamento mecânico, lubrificação mista. 


\begin{abstract}
This work concerns with experimental study of wear and friction responses of lubricated sliding system. Sliding tests were carried out using pin-on-disk wear testing machine for tests with continuous rotating movement, and the pin-on-plate device, for reciprocating tests between specimens. The metallic test coupons were AISI 52100 steel pins and AISI 8640 steel counter-faces. The used lubricant was paraffinic mineral oil, VI 100. The presence of additives and contamination in the lubricant oil were investigated under two mechanical loading levels, determined by the velocity/load relation. The wear was studied by means of optic and scanning electronic microscopes, perfilometry and dimensional analysis of the worn surfaces and oil analysis. The friction and the contact potential were monitored through out the sliding tests. The results showed that the wear of the metallic materials was susceptible to the mechanical loading, the additive and the contamination existence in the oil. It was observed differences among the wear results of the rotating and the reciprocating tests in terms of surface morphologies.
\end{abstract}

Key words: wear, friction, paraffinic oil, abrasive contaminant, rotating movement, reciprocating movement, mechanical loading, mixed lubrication. 


\title{
LISTA DE SÍMBOLOS
}

\section{Parâmetros numéricos}

$\alpha$ : $\quad$ nível de significância utilizado na análise estatística de dados

$\alpha$ : $\quad$ parâmetro do óleo da variação da viscosidade com a pressão $\left[\mathrm{Pa}^{-1}\right]$

$\eta$ : $\quad$ viscosidade dinâmica $[$ Pa.s $] ;\left[10^{3} \mathrm{cP}\right]$

$\lambda$ : $\quad$ fator de filme $=\mathrm{h} / \sigma$, com $\mathrm{h}=$ espessura do filme de lubrificante e $\sigma=$ rugosidade combinada das superfícies

$v_{\mathrm{i}}$ : $\quad$ coeficiente de Poisson do corpo i

$\tau$ : $\quad$ tensão de cisalhamento [MPa]

$\rho: \quad$ massa específica $\left[\mathrm{kg} / \mathrm{m}^{3}\right]$

$\sigma: \quad \quad \quad$ rugosidade combinada das superfícies $=\left(\sigma_{1}{ }^{2}+\sigma_{2}{ }^{2}\right)^{1 / 2}$, com $\sigma_{\mathrm{i}}$ na maioria das vezes considerada como sendo a rugosidade $\mathrm{Ra}_{\mathrm{i}}$ da superfície do corpo $\mathrm{i}(\mathrm{i}=1,2)$

$\gamma$ : deformação ao cisalhamento

$\Delta \mathrm{S}: \quad$ distância percorrida $[\mathrm{m}]$

E': $\quad$ módulo de elasticidade [MPa] combinado do contato, com

$1 / E^{\prime}=\left(1-v_{1}^{2}\right) / E_{1}+\left(1-v_{2}^{2}\right) / E_{2}, v_{i}=$ coeficiente de Poisson do corpo i e $E_{i}=$ módulo elástico do corpo i

$\mathrm{E}_{\mathrm{i}}$ : $\quad$ módulo de elasticidade $[\mathrm{MPa}]$ do corpo $\mathrm{i}$

k: $\quad$ coeficiente dimensional de desgaste do modelo de Archard [ $\mathrm{mm}^{3} /$ (N.m)]

h: $\quad$ espessura do filme de lubrificante [mm]

$\mathrm{H}: \quad$ dureza do material [MPa]

IV: $\quad$ índice de viscosidade do lubrificante

Q: $\quad$ volume de desgaste $\left[\mathrm{mm}^{3}\right]$

$\mathrm{R}$ : $\quad$ raio equivalente do contato [m], onde $1 / \mathrm{R}=1 / \mathrm{R}_{1}+1 / \mathrm{R}_{2}$, e $\mathrm{R}_{\mathrm{i}}=$ raio de contato do corpo $\mathrm{i}$

$\mathrm{R}_{\mathrm{i}}$ : $\quad$ raio de contato do corpo $\mathrm{i}[\mathrm{m}]$

Ra: $\quad$ parâmetro de rugosidade - altura média de asperezas $[\mu \mathrm{m}]$

$\mathrm{Ra}_{\mathrm{i}}$ : $\quad$ parâmetro de rugosidade - altura média de asperezas $[\mu \mathrm{m}]$ da superfície do corpo $\mathrm{i}$

Sm: parâmetro de rugosidade - espaçamento horizontal médio entre asperezas [mm]

P: $\quad$ pressão nominal de contato [MPa]

$\mathrm{P}_{\mathrm{Hmax}}$ : $\quad$ pressão máxima de Hertz [MPa]

$\mathrm{P}_{\text {Hnom: }}$ pressão nominal de Hertz (pressão nominal aplicada na área de Hertz) [MPa]

$\mathrm{V}: \quad$ velocidade de deslizamento $[\mathrm{m} / \mathrm{s}]$

$\mathrm{V}_{\text {med }}: \quad$ velocidade média $[\mathrm{m} / \mathrm{s}]$

W: $\quad$ carga normal $[\mathrm{N}]$

W': carga normal por unidade de comprimento $[\mathrm{N} / \mathrm{m}]$

$\mathrm{Z}: \quad$ viscosidade cinemática $\left[\mathrm{mm}^{2} / \mathrm{s}\right]$ ou $[\mathrm{cSt}]$

१V/W: parâmetro utilizado na curva de Stribeck, relaciona viscosidade do fluido lubrificante, velocidade de deslizamento e carga mecânica aplicada

\author{
Abreviaturas \\ EHL: elastohidrodinâmico \\ HD: hidrodinâmico \\ AES: espectroscopia de elétrons Auger
}


XPS: espectroscopia fotoeletrônica de raios-X

STEM: microscopia eletrônica de transmissão com varredura

MEV: microscópio eletrônio de varredura

EDAX: espectrometria de dispersão de energia de raios-X

IV: $\quad$ índice de viscosidade

EP: $\quad$ aditivo do lubrificante, que atuam em situações de extrema pressão

\section{Codificações}

P: $\quad$ ensaio oscilatório, maior carregamento

PP: $\quad$ ensaio oscilatório, menor carregamento

PPc: $\quad$ ensaio oscilatório, menor carregamento, óleo contaminado

D: ensaio rotativo, maior carregamento

DD: ensaio rotativo, menor carregamento

DDc: ensaio rotativo, menor carregamento, óleo contaminado

SA: ensaio com óleo sem aditivação

CA: ensaio com óleo com aditivação

c SA: ensaio com óleo sem aditivação e com contaminação

c CA: ensaio com óleo com aditivação e com contaminação

Mo: $\quad$ ensaio sob o maior nível de carregamento (283 $\mathrm{N}$ e velocidade menor)

Se: $\quad$ ensaio sob o menor nível de carregamento ( $80 \mathrm{~N}$ e velocidade maior) 


\section{LISTA DE FIGURAS}

\section{CAPÍTULO 1}

Figura 1-1: $\quad$ Mapas de desgaste de ensaios pino-sobre-disco, em função de velocidade e pressão normal, com diferentes lubrificantes, obtidos por AKAGAKI e KATO (1991). k: coeficiente dimensional de desgaste (conforme Eq. 2-15).

\section{CAPÍTULO 2}

Figura 2-1: $\quad$ Mudanças na configuração do contato como resultado do desgaste para uma esfera deslizando sobre um plano. A: somente a esfera se desgasta; B: somente o plano se desgasta; C: Ambos se desgastam. [BAYER, 1994]............................................. 11

Figura 2-2: $\quad$ Fatores que afetam a temperatura das superfícies [BAYER, 1994]........................... 13

Figura 2-3: $\quad$ Modelo utilizado por DRAGON-LOUISET (2001) para o desgaste produzido em um sistema deslizante com dois corpos (1 e 2) sob velocidade relativa V. $\Gamma_{1}, \Gamma_{2}$ : bordas limites entre a região afetada $\left(\Omega_{3}\right)$ e não afetada $\left(\Omega_{1}, \Omega_{2}\right)$ pelo deslizamento. e: espessura de $\Omega_{3}$.

Figura 2-4: $\quad$ Modelo da interface na escala microscópica, considerado por DRAGON-LOUISET (2001) para o modelo de desgaste no regime moderado de um sistema deslizante. $\Omega_{31}$ e $\Omega_{32}$ : regiões afetadas pelo processo deslizante; $\Omega_{33}$ : região com fluxo de partículas; $\Omega_{3}$ : região da interface.

Figura 2-5: $\quad$ Classificação de modos de desgaste, segundo HOKKIRIGAWA e colaboradores (1998).

Figura 2-6: Formação de cunha de fluido em um sistema deslizante lubrificado [BAYER, 1994]. . 22

Figura 2-7: Comparação dos contatos em um sistema com duas superfícies esféricas em deslizamento lubrificado no regime HD e EHL [BAYER, 1994].

Figura 2-8: $\quad$ Esquemas ilustrativos dos filmes de lubrificante formados em um contato lubrificado [NEALE, 1997].

Figura 2-9: $\quad$ Representação esquemática do diagrama de Stribeck: coeficiente de atrito em função da relação $\eta \mathrm{V} / \mathrm{W}$. $\eta$ : viscosidade, $\mathrm{V}$ : velocidade de deslizamento, $\mathrm{W}$ : carga normal [BAYER,1994].

Figura 2-10: Representação esquemática do diagrama de transição de regimes de lubrificação IRG [GEE, BEGELINGER e SALOMON, 1984].

Figura 2-11: $\quad$ Regimes de lubrificação e desgaste no deslizamento lubrificado de metais em função do fator $\lambda$, conforme HUTCHINGS (1992).

Figura 2-12: $\quad$ Efeito do comprimento da cadeia molecular no coeficiente de atrito e no ângulo de contato; esfera de aço inoxidável contra vidro coberto com uma monocamada de lubrificante [BOWDEN e TABOR, 1964].

Figura 2-13: Efeito do comprimento da cadeia molecular e dos grupos terminais no coeficiente de atrito e no ângulo de contato; esfera de aço inoxidável contra vidro coberto com uma monocamada de lubrificante [BOWDEN, TABOR, 1964].

Figura 2-14: Desgaste em ensaios "four ball”, em função da concentração de contaminante [ODIOWEI e ROYLANCE, 1986].

Figura 2-15: Resultados do coeficiente de atrito obtidos em ensaios "four ball" em função da concentração de contaminante [ODI-OWEI e ROYLANCE, 1986] .............................56 
Figura 2-16: Estrutura molecular do ZDDP, aditivo destinado a condição de operação sob extrema pressão [WANG, CHENG e GUAN, 1995].

Figura 2-17: $\quad$ Partículas de desgaste resultantes de ensaios lubrificados (A) sem e (B) com aditivo ZDDP, observação em STEM, e respectivos padrões de difração de elétrons [MARTIN et al., 1986]. .59

Figura 2-18: $\quad$ Espectros de energia de raios-X obtidos (A) no STEM e (B) no MEV, da região amorfa das partículas de desgaste produzidas nos ensaios com aditivo [MARTIN et al., 1986]. 60

Figura 2-19: Imagens topográficas por MEV das superfícies de desgaste obtidas em ensaio lubrificados [JAHANMIR, 1987].....

Figura 2-20: Taxas de desgaste em função da carga obtidas em ensaio lubrificados [JAHANMIR, 1987].

Figura 2-21: Desgaste resultante de ensaios bloco-sobre-anel com e sem a presença do aditivo no lubrificante. (A) cerâmica (zircônia parcialmente estabilizada); (B) metal (AISI 52100) [WANG, CHENG e GUAN, 1995]....

Figura 2-22: $\quad$ Micrografia das trilhas de desgaste do material cerâmico, evidenciando a formação de filme na trilha no ensaio com ZDDP (foto da direita). [WANG, CHENG e GUAN, 1995].

Figura 2-23: $\quad$ Espectros obtidos por XPS da superfície de desgaste do material metálico, na região do (A) Zn, (B) O, (C) P [WANG, CHENG e GUAN, 1995].

Figura 2-24: $\quad$ Molécula do aditivo de extrema pressão utilizado por WAN e colaboradores (1996) em ensaios de deslizamento lubrificado.

Figura 2- 25: $\quad$ Micrografias da área de desgaste (aço AISI 52100) originadas em ensaios com carga de $300 \mathrm{~N}$, (a) sem e (b) com aditivo [WAN et al., 1996].

Figura 2-26: Percentual de elementos químicos encontrados na superfície de desgaste ensaiada com lubrificante e $1 \%$ de aditivo, resultante da análise por AES [WAN et al., 1996].........65

Figura 2-27: $\quad$ Desgaste linear do anel de pistão de $1^{\circ}$ canalete em função da rugosidade inicial (c: carga = 1,43 bhp, sendo a potência máxima "engine rated power" $6 \mathrm{bhp}$ ) [SREENATH, RAMAN, 1976].

Figura 2-28: $\quad$ Perfis de rugosidade ( $\mathrm{Ra}$ de $0,2 \mu \mathrm{m}, 0,5 \mu \mathrm{m}$ e $0,8 \mu \mathrm{m}$ ) dos cilindros de motor de combustão interna [SREENATH e RAMAN, 1976].

Figura 2-29: Curvas de desgaste do pino obtidas por MEHAN (1988), antes e após a adição de abrasivo $\mathrm{Al}_{2} \mathrm{O}_{3}$ no óleo; ensaios pino-sobre-disco, "like-on-like". (A) Aço AISI 440C; (B) Revestimento de carboneto de tungstênio com $0,15 \mathrm{~mm}$ de espessura.

Figura 2-30: $\quad$ Resultados de desgaste de ensaios lubrificados com óleo diesel a $177{ }^{\circ} \mathrm{C}$, tipo blocosobre-anel com movimento alternado. (A) Desgaste do anel de $\mathrm{WC}+\mathrm{Co}$, mediante 6 materiais de bloco. (B) Desgaste dos materiais do bloco (segmento de anel de pistão revestidos com $\mathrm{WC}+\mathrm{Co}, \mathrm{Cr}$ e $\mathrm{Cr}_{3} \mathrm{C}_{2}$ ), mediante o anel de $\mathrm{WC}+\mathrm{Co}$ [MEHAN, FLYNN e GLAMMARISE, 1991].

Figura 2-31: Resultados de desgaste obtidos em ensaios "four ball" modificado, em função da contaminação do óleo [ODI-OWEI e ROYLANCE, 1987].

Figura 2-32: Curvas das cargas e velocidades relativas à transição I-II do diagrama IRG, resultantes de ensaios "four ball" modificado, com óleo não contaminado [ODI-OWEI e ROYLANCE, 1987]. 75

Figura 2-33: Cargas para a ocorrência de falha do filme de lubrificante, obtidas em ensaios "four ball” modificado, em função da contaminação do óleo [ODI-OWEI e ROYLANCE, 1987].

Figura 2-34: Efeito das razões de dureza no desgaste abrasivo a três corpos [XUAN, HONG e FITCH, 1989]. 
Figura 2-35: Indentação e corte provocados por uma partícula abrasiva em meio lubrificado [XUAN,

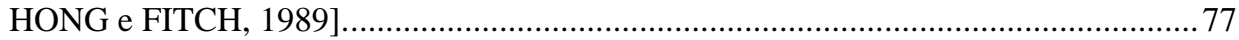

Figura 2-36: Resultados de KHURSHUDOV, DROZDOV e KATO (1995), de ensaios bloco-sobreanel lubrificado. (A): Coeficiente de atrito vs. velocidade; (B) Coeficiente de atrito vs. temperatura de ensaio (ou viscosidade do óleo); (C) Taxa de desgaste do aço vs. velocidade; (D) Taxa de desgaste da cerâmica vs. velocidade.

Figura 2-37: Fator de filme $\lambda$, inicial e final, em função das velocidades ensaiadas. Região I corresponde à lubrificação mista com efeito dominante da interação mecânica e com efeito EHL crescente com o aumento da velocidade; região II refere-se à lubrificação mista com efeito EHL predominante [KHURSHUDOV, DROZDOV e KATO, 1995].81

Figura 2-38: Coeficiente de atrito obtido nos ensaios lubrificados pino-sobre-disco realizados por JISHENG e GAWNE (1997); diâmetro do pino de 6,35 mm, carga de 450 N. ............82

Figura 2-39: Coeficiente de atrito em função da carga de ensaio, obtido por JISHENG e GAWNE (1997); ensaios pino-sobre-disco lubrificados, diâmetro do pino de 6,35 mm..............83

Figura 2-40: $\quad$ Relação entre o coeficiente de atrito e o fator $(\eta \mathrm{V}) /(\mathrm{P} \sigma)$ dos ensaios realizados por JISHENG e GAWNE (1997).

Figura 2-41: Tensão elétrica entre pino e disco medida durante os ensaios pino-sobre-disco lubrificados de JISHENG e GAWNE (1997)............................................................. 84

Figura 2-42: $\quad$ Superfície observada por JISHENG, GAWNE (1997) após ensaio lubrificado, com carga de $300 \mathrm{~N}$.

Figura 2-43: $\quad$ Superfície observada por JISHENG, GAWNE (1997) após ensaio lubrificado, com carga de $900 \mathrm{~N}$.

Figura 2-44: Resultados de desgaste não lubrificado de aço contra aço, de tribossistemas com movimento contínuo e com movimento oscilatório ("reciprocating") [WARD, 1970]. 87

\section{CAPÍTULO 3}

Figura 3-1: $\quad$ Configuração geométrica dos dispositivos utilizados para os ensaios.

Figura 3-2: $\quad$ Esquema para visualização da relação do movimento rotativo com o movimento alternado. Observação da variação da velocidade relativa no ensaio P e PP, obtida com base na Eq. 3-1.

Figura 3-3: $\quad$ Esquema de parte do conjunto mecânico do equipamento de ensaio, com visualização do posicionamento das células de carga e do sensor de deslocamento vertical do pino.94

Figura 3-4: $\quad$ Fotos microscópicas típicas de representação das morfologias observadas na análise ferrográfica de amostras de óleo.

Figura 3-5: $\quad$ Microestrutura do material dos pinos (aço AISI 52100), observada em microscópio óptico, 500x. Ataque Nital 3\%. Nota-se uma estrutura homogênea (martensítica) muito fina.

Figura 3-6: $\quad$ Microestrutura do material dos pinos (aço AISI 52100), ataque Nital 3\%, observada em MEV, imagem de elétrons retroespalhados. Nota-se uma microestrutura martensítica fina e presença de carbonetos.

Figura 3-7: $\quad$ Calota esférica da extremidade do pino medida com um perfilômetro.

Figura 3-8: $\quad$ Observação por microscópio óptico da superfície da extremidade arredondada do pino, sem ataque, 100x (esquerda) e 500x (direita). Nota-se a presença de microcrateras. ....99

Figura 3-9: $\quad$ Perfil de rugosidade da superfície da extremidade de um pino.................................99

Figura 3-10: Observação por microscópio óptico da microestrutura do material das placas (aço SAE 8640), 500x. Ataque Nital 3\%. Nota-se uma estrutura martensítica fina......... 
Figura 3-11: Observação por microscópio óptico da microestrutura do material das placas (aço SAE 8640), 200x. Ataque Nital 3\%. Região com sulfeto.

Figura 3-12: Microestrutura do material SAE 8640 das placas e dos discos, ataque Nital 3\%, observada em MEV, imagem por elétrons retroespalhados. Nota-se a mesma estrutura, tipicamente martensítica, em ambas as micrografias.

Figura 3-13: $\quad$ Esquema para visualização do direcionamento do acabamento superficial nas amostras de discos e placas (indicado pelo tracejado).

Figura 3-14: $\quad$ Superfícies de um disco e de uma placa, observadas por microscópio óptico (100x).. 102

Figura 3-15: $\quad$ Perfil de rugosidade da superfície de uma placa, na direção do deslizamento............. 103

Figura 3-16: Espectros de transmitância na região do infravermelho obtidos para os três óleos selecionados para os ensaios.

Figura 3-17: Histograma da distribuição do tamanho de partículas do material quartzo utilizado como abrasivo na forma de pó.

Figura 3-18: Partículas do pó abrasivo a ser utilizado nos ensaios com lubrificante contaminado, observadas por microscópio óptico (500x)......

Figura 3-19: Partículas do pó abrasivo a ser utilizado nos ensaios com lubrificante contaminado, observadas por MEV, imagem de elétrons secundários. ........................................... 109

Figura 3-20: Aparência do óleo com e sem abrasivo.................................................................. 110

Figura 3-21: Diagrama de lubrificação de GEE, BEGELINGER, SALOMON (1984) com as condições de ensaio utilizadas.

\section{CAPÍTULO 4}

Figura 4-1: $\quad$ Gráficos da posição vertical do pino (WEAR) ao longo dos ensaios (A) Pc SA e (B) D SA. .

Figura 4-2: $\quad$ Média e desvio-padrão do deslocamento vertical do pino em função da condição de ensaio.

Figura 4-3: $\quad$ Modelo para cálculo do volume aproximado de desgaste do pino.

Figura 4-4: Aspecto geral de duas superfícies de pino após ensaiados, observados em MEV, imagem de elétrons secundários. A linha tracejada delimita a área de desgaste.

Figura 4-5: $\quad$ Formação do sulco na trilha de desgaste sobre o contra-corpo, resultando em uma área de desgaste do pino elíptica.

Figura 4-6: $\quad$ Aparência microscópica da superfícies metálicas após o ensaio de deslizamento (100x), condição PP.

Figura 4-7: $\quad$ Aparência microscópica da superfícies metálicas após o ensaio de deslizamento (100x), condição PPc.

Figura 4-8: $\quad$ Aparência microscópica da superfícies metálicas após o ensaio de deslizamento (100x), condição DD.

Figura 4-9: $\quad$ Aparência microscópica da superfícies metálicas após o ensaio de deslizamento (100x), condição DDc.

Figura 4-10: Aparência microscópica da superfícies metálicas após o ensaio de deslizamento (100x), condição P.

Figura 4-11: $\quad$ Aparência microscópica da superfícies metálicas após o ensaio de deslizamento (100x), condição D.

Figura 4-12: Aparência microscópica da superfícies metálicas após o ensaio de deslizamento (100x), condição Pc. 
Figura 4-13: Aparência microscópica da superfícies metálicas após o ensaio de deslizamento (100x), condição Dc.

Figura 4-14: Esquema indicativo da localização da região na área de desgaste dos pinos observados no MEV, delimitada pelo quadrado vermelho.

Figura 4-15: Aparência microscópica da área de desgaste de pinos após ensaio nas condições DD e D. Imagens de elétrons secundários.

Figura 4-16: Aparência microscópica da área de desgaste de pinos após ensaio na condição P. Imagens de elétrons secundários.

Figura 4-17: $\quad$ Espectro obtido por EDAX referente à análise química da região escura indicada no pino do ensaio P6 CA.

Figura 4-18: Esquema indicativo das regiões das trilhas das placas e dos discos observados no MEV, delimitadas pelos quadrados vermelhos.

Figura 4-19: Aparência microscópica da trilha de desgaste de placas após ensaio na condição PP, região próxima à extremidade lateral. Imagens de elétrons secundários.

Figura 4-20: $\quad$ Espectro obtido por EDAX referente à análise química da região escura indicada na placa do ensaio PP6 CA.

Figura 4-21: Aparência microscópica da trilha de desgaste de placas após ensaio na condição PP, região central da trilha, evidenciando partículas nos sulcos do acabamento original. Imagens de elétrons secundários.

Figura 4-22: Aparência microscópica da trilha de desgaste de placas após ensaio na condição P, região próxima à extremidade lateral da trilha. Imagens de elétrons secundários......... 138

Figura 4-23: $\quad$ Espectro obtido por EDAX referente à análise química da superfície da extremidade lateral da placa do ensaio P6 CA.

Figura 4-24: Região sub-superficial afetada pelo desgaste da placa do ensaio P6 (CA), ataque Nital $3 \%$, imagens de elétrons retroespalhados.

Figura 4-25: Região sub-superficial afetada pelo desgaste da placa do ensaio P1 (SA), ataque Nital $3 \%$, imagens de elétrons retroespalhados.............................................................. 140

Figura 4-26: Aparência microscópica das superfícies de disco após ensaio na condição D. Imagens de elétrons secundários.

Figura 4-27: $\quad$ Espectro obtido por EDAX referente à análise química na região do sulco da superfície do disco do ensaio D4 CA.

Figura 4-28: Aparência microscópica da trilha de desgaste do disco do ensaio D4, com detalhe do microtrincamento e a aparente pré-formação de uma partícula de desgaste. Imagem de elétrons secundários.

Figura 4-29: Região sub-superficial afetada pelo desgaste do disco do ensaio D4 (CA), ataque Nital $3 \%$, imagens de elétrons retroespalhados.

Figura 4-30: Visualização da região sub-superficial afetada pelo desgaste do disco do ensaio D6 (SA), ataque Nital 3\%, imagens de elétrons retroespalhados..................................... 144

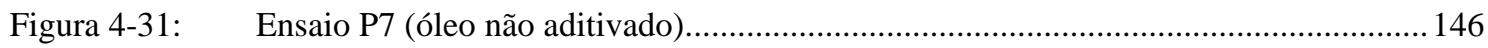

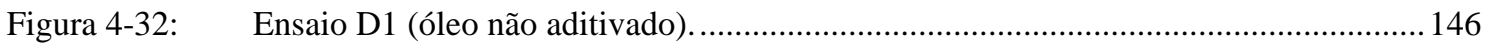

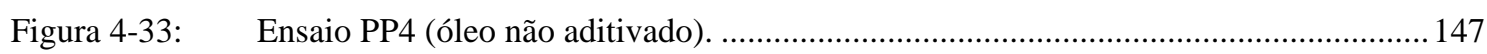

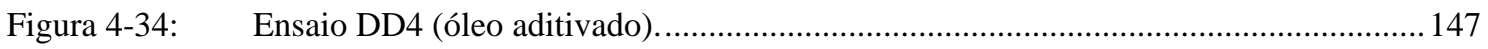

Figura 4-35: Valores normalizados da área projetada de desgaste do pino resultantes dos ensaios

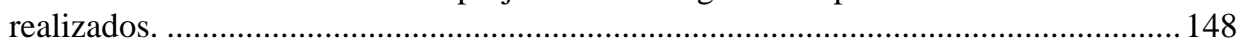

Figura 4-36: Valores normalizados da área de desgaste do pino resultantes dos ensaios com menor carregamento (A) e maior carregamento (B). Efeito da utilização do contaminante no óleo. 
Figura 4-37: Valores normalizados da área de desgaste do pino resultantes dos ensaios com menor carregamento (A) e maior carregamento (B). Efeito da utilização do óleo com aditivo.

Figura 4-38: Valores normalizados da área de desgaste do pino resultantes dos ensaios rotativos (A) e oscilatórios (B). Efeito do carregamento mecânico (condição de velocidade e carga). 151

Figura 4-39: Valores normalizados da área de desgaste do pino em função da condição de ensaio; visualização das diferenças entre os sistemas mecânicos......

Figura 4-40: Ilustração esquemática de duas situações de desgaste nos ensaios. (1) Desgaste preferencial do contra-corpo; (2) Desgaste preferencial do pino.

Figura 4-41: Diferença percentual do comprimento das diagonais ortogonais, $\mathrm{V}$ e $\mathrm{H}$, da área elíptica do pino.

Figura 4-42: $\quad$ Posicionamento do apalpador do rugosímetro sobre uma amostra de placa para medição do perfil na direção transversal da trilha formada no ensaio.

Figura 4-43: Ilustração do procedimento adotado para as medições do perfil da área de desgaste do pino.

Figura 4-44: $\quad$ Perfis dos pinos após ensaiados, obtidos pelo rugosímetro; condições de ensaio PP SA e PPc SA.

Figura 4-45: $\quad$ Perfis dos pinos após ensaiados, obtidos pelo rugosímetro; condições PP CA e PPc CA.

Figura 4-46: Perfis dos pinos após ensaiados, obtidos pelo rugosímetro; condições de ensaio DD SA

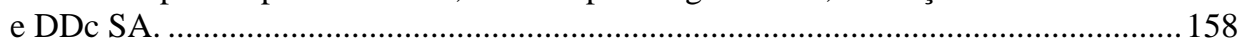

Figura 4-47: $\quad$ Perfis dos pinos após ensaiados, obtidos pelo rugosímetro; condições de ensaio DD CA

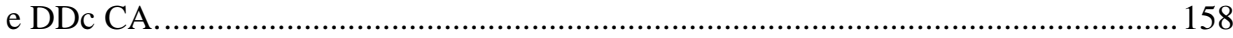

Figura 4-48: $\quad$ Perfil de um disco DD CA após ensaiado, obtido pelo rugosímetro. 159

Figura 4-49: $\quad$ Perfil de uma placa nova e de uma após ensaiada (PPc CA), direção longitudinal ao deslizamento, obtidos pelo rugosímetro. 159

Figura 4-50: $\quad$ Perfil longitudinal da placa, antes e após ensaio, condição PP CA. 160

Figura 4-51: $\quad$ Perfis dos pinos e das respectivas placas após ensaiados, obtidos pelo rugosímetro; condições P SA e P CA.

Figura 4-52: $\quad$ Perfil longitudinal da placa após ensaio, condição P CA.

Figura 4-53: Perfis dos pinos e dos respectivos discos após ensaiados, obtidos pelo rugosímetro; condições D SA e D CA. 161

Figura 4-54: Perfis dos pinos e das respectivas placas após ensaiados, obtidos pelo rugosímetro; condições Pc SA e Pc CA.

Figura 4-55: $\quad$ Perfis dos pinos e dos respectivos discos após ensaiados, obtidos pelo rugosímetro; condições Dc SA e Dc CA.

Figura 4-56: $\quad$ Áreas de desgaste do pino e do contra-corpo sobrepostas, para visualização da largura da região afetada; condição Pc SA.

Figura 4-57: Rugosidade $\mathrm{Ra}[\mu \mathrm{m}]$ da superfície dos pinos, antes e após o ensaio, em função da condição de ensaio. (A) ensaios oscilatórios; (B) ensaios rotativos.

Figura 4-58: Comportamento do potencial de contato nos ensaios realizados nas condições (A) PP SA e (B) PP CA.

Figura 4-59: Comportamento do potencial de contato nos ensaios realizados na condição (A) PPc SA e (B) PPc CA.

Figura 4-60: Comportamento do potencial de contato nos ensaios realizados nas condições (A) P SA e (B) P CA. 
Figura 4-61: Comportamento do potencial de contato nos ensaios realizados nas condições (A) DD SA e (B) DD CA.

Figura 4-62: Comportamento do potencial de contato nos ensaios realizados nas condições (A) D SA

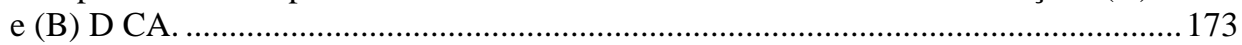

Figura 4-63: Gráfico com os valores médios do potencial de contato dos ensaios realizados e resultados da análise estatística dos efeitos da contaminação, aditivação e carregamento no potencial.

Figura 4-64: $\quad$ Potencial de contato em função da condição de ensaio; visualização das diferenças entre os sistemas mecânicos. Valores em destaque referem-se àqueles com as maiores diferenças.

Figura 4-65: Gráficos do coeficiente de atrito em função do tempo, ensaios oscilatórios com menor carregamento. (A) com óleo não aditivado; (B) com óleo aditivado.

Figura 4-66: Gráficos do coeficiente de atrito em função do tempo, ensaios oscilatórios com maior carregamento. (A) com óleo não aditivado; (B) com óleo aditivado.

Figura 4-67: Gráficos do coeficiente de atrito em função do tempo, ensaios rotativos com menor carregamento. (A) com óleo não aditivado; (B) com óleo aditivado.

Figura 4-68: Gráficos do coeficiente de atrito em função do tempo, ensaios rotativos com maior carregamento. (A) com óleo não aditivado; (B) com óleo aditivado.

Figura 4-69: Detalhe de curvas do coeficiente de atrito em função do tempo, ensaios com óleo não aditivado. (A) oscilatórios; (B) rotativos.

Figura 4-70: Gráfico com os valores médios do coeficiente de atrito dos ensaios realizados e resultados da análise estatística dos efeitos da contaminação, aditivação e carregamento no potencial.

Figura 4-71: Coeficiente de atrito em função da condição de ensaio; visualização das diferenças entre os sistemas mecânicos. Valores em destaque referem-se àqueles com diferença significativa. 186

\section{CAPÍtulO 5}

Figura 5-1: $\quad$ Esquemas ilustrativos do contato entre pino e disco e pino e placa, ressaltando a diferença na angulosidade das asperezas devido à diferença no valor de Ra.

Figura 5-2: $\quad$ Trilhas de desgaste nas superfícies de uma amostra de placa e de disco, imediatamente após a realização do ensaio, observação da geometria da aglomeração de resíduos próximo à trilha.

Figura 5-3: $\quad$ Perfil transversal da trilha de desgaste do disco do ensaio D8 CA.

Figura 5-4: $\quad$ Aproximações geométricas utilizadas para o cálculo do volume de desgaste do contracorpo e dos respectivos coeficientes de desgaste, $\mathrm{k}$, para as condições de ensaio P e D.

Figura 5-5: Valores do coeficiente de desgaste $\mathrm{k}^{\prime}$, calculados pela área do pino afetada pelo desgaste, em função da condição de ensaio...

Figura 5-6: Diagrama esquemático utilizado por BLAU (1994), relacionando a espessura do filme de óleo com o atrito e o desgaste. Em vermelho indica-se a região provável dos ensaios realizados.

Figura 5-7: Valores do coeficiente de desgaste k", calculados pela área do pino afetada pelo desgaste, em função da condição de ensaio.....

Figura 5-8: $\quad$ Área de desgaste do pino normalizada, em função da relação $\mathrm{V}_{\text {med }}$ /W. (A) Ensaios CA, (B) CA contaminado, (C) SA, (D) SA contaminado.

Figura 5-9: $\quad$ Área de desgaste do pino normalizada, em função da relação $\mathrm{V}_{\text {med }} / \mathrm{W}$. 198 
Figura 5-10: $\quad$ Área de desgaste do pino normalizada, em função da relação $\left(\mathrm{V}_{\text {med }} / \mathrm{W}\right) / \sigma$. (A) Ensaios CA, (B) CA contaminado, (C) SA, (D) SA contaminado. ....................................... 199

Figura 5-11: Área de desgaste do pino normalizada, em função da relação $\left(\mathrm{V}_{\text {med }} / \mathrm{W}\right) / \sigma \ldots \ldots \ldots \ldots . . . . . . .200$

Figura 5-12: Esquema ilustrativo do contato deslizante e a localização do filme EHD (ou EHL)...201

Figura 5-13: Área de desgaste do pino normalizada, em função da relação $V_{\text {med }}^{0,68} / \mathrm{W}^{0,07}$. (A) Ensaios CA, (B) CA contaminado, (C) SA, (D) SA contaminado. ........................................ 201

Figura 5-14: $\quad$ Área de desgaste do pino normalizada, em função da relação $\mathrm{V}_{\text {med }}{ }^{0,68} / \mathrm{W}^{0,07} \ldots \ldots \ldots \ldots . . . . . .202$

Figura 5-15: Área de desgaste do pino normalizada, em função da relação $\left(\mathrm{V}_{\text {med }}^{0,68} / \mathrm{W}^{0,07}\right) / \sigma$. (A) Ensaios CA, (B) CA contaminado, (C) SA, (D) SA contaminado............................. 202

Figura 5-16: Área de desgaste do pino normalizada, em função da relação $\left(\mathrm{V}_{\text {med }}{ }^{0,68} / \mathrm{W}^{0,07}\right) / \sigma \ldots \ldots . .203$

Figura 5-17: Valores médios do coeficiente de atrito, em função dos fatores (A) $\mathrm{V}_{\text {med }} / \mathrm{W}$, (B)

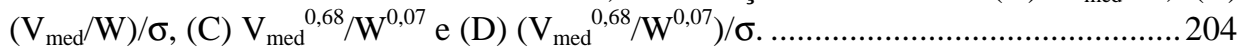

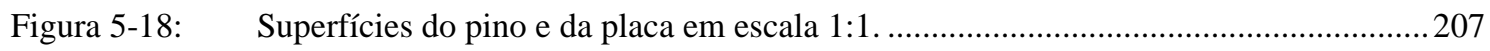




\section{LISTA DE TABELAS}

\section{CAPÍTULO 2}

Tabela 2-1: $\quad$ Energia de ligação (eV) dos elementos $\mathrm{S}, \mathrm{N}$ e O obtidos da análise do aditivo e da trilha de desgaste [WAN et al., 1996]............................................................................... 66

Tabela 2-2: $\quad$ Energia de ligação S 2p (eV) de compostos de enxofre de referência [WAN et al.,

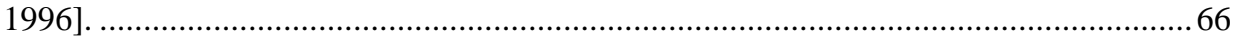

\section{CAPÍTULO 3}

Tabela 3-1: Quadro-resumo com as 16 condições estudadas. .....................................................90

Tabela 3-2: $\quad$ Composição química nominal e medida do aço AISI-SAE 52100............................... 97

Tabela 3-3: $\quad$ Composição química nominal e medida do aço AISI-SAE 8640............................... 100

Tabela 3-4: Valores da rugosidade Ra das superfícies dos contra-corpos, medidas na direção do

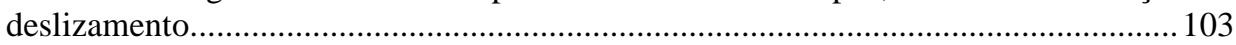

Tabela 3-5: $\quad$ Valores da rugosidade Ra das superfícies dos contra-corpos, considerando a média dos dois lotes. 104

Tabela 3-6: $\quad$ Valores da rugosidade média equivalente do par de amostras, $\sigma=\left(\sigma_{1}{ }^{2}+\sigma_{2}{ }^{2}\right)^{1 / 2} \ldots \ldots . .104$

Tabela 3-7: Valores da distância média entre asperezas, Sm, das superfícies dos contra-corpos, medidas na direção do deslizamento do ensaio.

Tabela 3-8: $\quad$ Viscosidade cinemática, índice de viscosidade e TAN dos óleos selecionados para os ensaios.

Tabela 3-9: Elementos detectados, em unidades de $\mu \mathrm{g} / \mathrm{g}$, na análise espectrométrica dos óleos selecionados para os ensaios. 106

Tabela 3-10: $\quad$ Quadro-resumo com as condições de ensaio utilizadas. 112

\section{CAPÍTULO 4}

Tabela 4-1: $\quad$ Diagrama com as condições de ensaio estudadas, mostrando os códigos e as repetições realizadas em cada condição.

Tabela 4-2: $\quad$ Figuras relativas às microfotografias e respectivas condições de ensaio. 122

Tabela 4-3: $\quad$ Principais características morfológicas visualizadas em cada condição de ensaio......

Tabela 4-4: $\quad$ Valores médios e normalizados da área afetada no ensaio medida no pino, resultantes em cada condição de ensaio.

Tabela 4-5: $\quad$ Ações causadas no contato pelo tipo de influência.

Tabela 4-6: $\quad$ Diferença percentual nas áreas de desgaste do pino normalizadas resultantes dos ensaios com menor e maior nível de carregamento.

Tabela 4-7: $\quad$ Condições que apresentaram maior percentual de tendência à forma elíptica na área do pino afetada pelo desgaste.

Tabela 4-8: $\quad$ Condições de ensaio que apresentaram efeito contrário na comparação do tamanho da área do pino afetada pelo desgaste e da diferença entre as diagonais ortogonais da área. 
Tabela 4-9: $\quad$ Resumo das principais características relacionadas ao desgaste observadas em cada

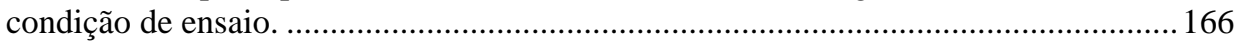

Tabela 4-10: Resumo das principais características relacionadas ao comportamento do potencial de contato observadas em cada condição de ensaio..................................................... 177

Tabela 4-11: Resumo das principais características relacionadas ao comportamento do coeficiente de atrito observadas em cada condição de ensaio.

\section{CAPÍTULO 5}

Tabela 5-1: $\quad$ Principais diferenças entre os ensaios com os dois sistemas de ensaio utilizados........ 190

Tabela 5-2: $\quad$ Relação de velocidade e carga das condições de ensaio utilizadas. ............................. 196

Tabela 5-3: Valores utilizados para o cálculo da espessura do filme lubrificante do regime EHL, conforme Eq. 2-10, e espessuras resultantes. 


\section{LISTA DE EQUAÇÕES}

\section{CAPÍTULO 2}

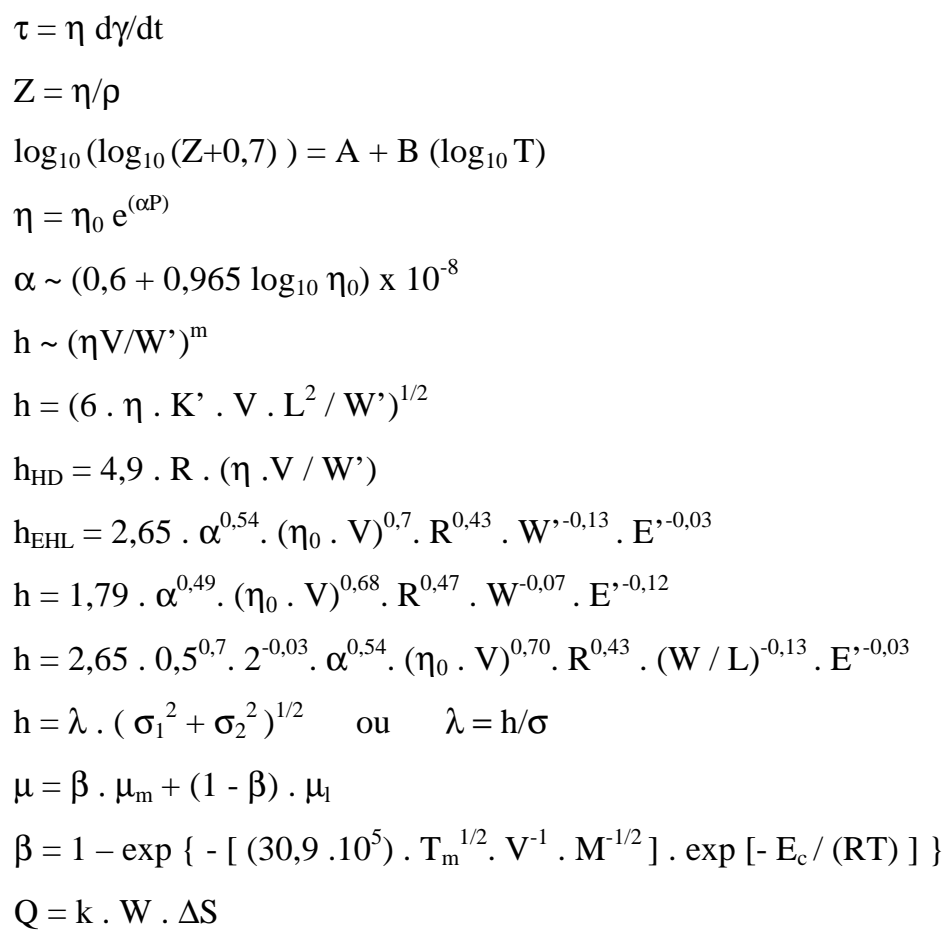

Eq. 2-1 ............................ 22

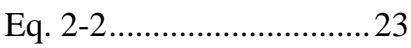

Eq. $2-3$............................. 23

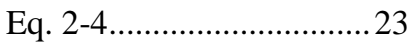

Eq. $2-5$............................. 24

Eq. 2-6.............................. 25

Eq. 2-7 ............................. 25

Eq. 2-8 ........................... 28

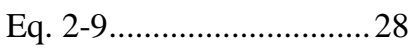

Eq. $2-10$........................... 28

Eq. $2-11 \ldots \ldots \ldots \ldots \ldots \ldots \ldots \ldots . . . . . . . . . . . . . .28$

Eq. 2-12 ........................... 30

Eq. $2-13$.......................... 34

Eq. $2-14 \ldots \ldots \ldots \ldots \ldots \ldots \ldots \ldots . . . . . . . . . . . . . .35$

Eq. $2-15 \ldots \ldots \ldots \ldots \ldots \ldots \ldots \ldots . . . . . . . . . . . . .22$

\section{CAPÍTULO 3}

$v=2 . \pi . f . R . \operatorname{sen}(\theta)$

Eq. 3-1 91

$\mathrm{V}_{\text {med }}=\frac{1}{\pi} \int_{0}^{\pi} 2 . \pi . \mathrm{f} . \mathrm{R} . \operatorname{sen} \theta \mathrm{d} \theta=4$.f .R

Eq. 3-2. 92

$\mathrm{P}_{\text {Hmáx }}=0,918\left[\mathrm{~W} /\left(\mathrm{D} / \mathrm{E}^{\prime}\right)^{2}\right]^{1 / 3}$

Eq. 3-3 112

$a=0,721\left(W . D / E^{\prime}\right)^{1 / 3}$

Eq. 3-4 112

\section{CAPÍTULO 5}

$\mathrm{k}^{\prime}=\mathrm{Q}^{\prime} / \mathrm{W} . \Delta \mathrm{S} \quad$ ou $\quad \mathrm{k}^{\prime}=$ área normalizada/W

Eq. $5-1$. 194

$\mathrm{k} "=\left(\mathrm{Q}^{\prime} \cdot \mathrm{W}\right) /\left(\mathrm{V}_{\text {med }} \cdot \Delta \mathrm{S}\right) \quad$ ou $\quad \mathrm{k}$ " = área normalizada $. \mathrm{W} / \mathrm{V}_{\text {med }}$

Eq. 5-2 196 